\title{
Case Report: The Physiology of a Preventable Near Death in a Hot Tub
}

\author{
Bruce Becker ${ }^{1}$ \\ ${ }^{1}$ University of Washington School of Medicine
}

July 13, 2021

\begin{abstract}
This is a case report of a very preventable near-death event involving a 6-year-old female who had a syncopal event due to hyperthermia in an overheated hot tub and drowned. She was resuscitated but due to the combination of anoxia and hyperthermia has been left with permanent brain damage.
\end{abstract}

The Physiology of a Preventable Tragedy: Near Death in a Hot Tub Author:

Bruce E. Becker, MD, MS, FACSM

Clinical Professor

University of Washington School of Medicine

Corresponding Author:

Bruce E. Becker, MD, MS, FACSM

beckerb2@uw.edu

Keywords:

Hyperthermia

Anoxia

Traumatic brain injury

Pediatric

Aquatic immersion

Hot Tubs

\section{Key Clinical Message:}

Hyperthermia in children is a well-recognized risk due to enclosed vehicles.Exposure to an overheated hot tub poses a real risk in children due to unique pediatric physiology. This physiology should be better understood by medical professionals

\section{Abstract:}

Hot tubs are a common source of relaxation and recreation. While recommendations exist for tub temperatures and guidelines regarding their use by children and adults with potential risk factors, these are 
commonly ignored. Environmental factors such as solar gain may dramatically alter tub temperatures well beyond those set by the regulating thermostat, as tubs have no cooling mechanisms. This article describes a situation involving a hot tub with tragic consequences, referencing the underlying physiology and describing means of prevention of such adverse consequences.

\section{The Case Study:}

Mid-afternoon on a very hot day in August in the southern United States, a mother, her two children and a friend entered a hotel water park, anticipating a relaxing afternoon in the water playground. This was not intended as an area for adults except as observers and guardians for their children. It was filled with several slides, and many spray venues, both overhead and ground level. In a corner of the area was a circular hot tub, a carry-over from the previous facility which was more adult-centric with a full pool.

The temperature was $100^{\circ}$ on this cloudless day following a lengthy period of extended heat wave. The environment looked very appealing. The mother and her children sat on recliners in the vicinity of the hot tub which was empty at the time and still. The mother assumed because the jets were not on that the tub had been turned off. The younger children asked if they could go into the hot tub. The mother consented, and the two youngest entered the tub using the stairs. The youngest child exited to play in the spray features, and the 6-year-old, a skilled swimmer, remained in the tub seated on the bench edge inside the tub with water nearly reaching her neck. The mother was observing all of the children across the area while her oldest child departed to change into his swim suit. As he returned from the changing room, he saw that his sister was face down in the tub and called to his mother. The mother and brother immediately pulled the unconscious girl from the tub onto the concrete pool deck, calling for help. A nurse visiting in the pool area was alerted to the situation, ran to the child and assessed her, finding no pulse or respiration. She asked for a towel to be placed under her and immediately initiated CPR with another medical professional pool guest assisting. 911 was called. After several cycles of CPR, the young girl began breathing and her pulse returned, She vomited frothy material, but she remained unconscious. EMTs arrived and assessed the situation, supplying oxygen via facemask, and noting labored respiration, with lungs, sounding wet. They recorded that her skin was very hot to touch and that the young girl was unconscious with a Glasgow score of 8 . She was then evacuated on a to the closest emergency room after their arrival. In route she had a seizure, without any prior seizure history. Her temperature on ED arrival was $104.7^{\circ} \mathrm{F}$. She remained very febrile for a period of days with very low consciousness scores. Medical imaging demonstrated significant brain injury. After a series of transfers between hospitals over a period of several weeks she was discharged to home with very apparent severe brain damage. Years later, she remains very impaired.

\section{The Physical Environment:}

The hot tub thermostat had been set at $102^{\circ} \mathrm{F}$, although on the day prior and subsequently during the early morning, the County inspector had measured the actual tub temperature at $104^{\circ} \mathrm{F}$. This event happened in mid-late afternoon, allowing solar gain to heat the hot tub well beyond $104^{\circ} \mathrm{F}$. A systems engineer using finite element analysis estimated the tub temperature to be between $106^{\circ}-109^{\circ} \mathrm{F}$. on the day of the event. Using the same methodology, the temperature of the surrounding concrete was estimated at $139^{\circ} \mathrm{F}$. As a consequence of the solar gain on both tub and concrete, this was a particularly dangerous environment for the risk of hyperthermia.

\section{The Physiology:}

\section{Hyperthermia}

Hyperthermia in children is quite common, potentially occurring post-exercise, and environmentally, such as when inside enclosed cars. ${ }^{1}$ The number of hot tub thermal injuries is unknown. That said, at a temperature of $34^{\circ} \mathrm{C}$, the only effective means of body cooling is through the evaporation of perspiration, and within a hot water environment there is no evaporative loss. ${ }^{2}, 3$ Since there is no effective biologic means of temperature reduction, hot water immersion poses a substantial potential physiologic risk for both children and adults. Children are more susceptible to hyperthermia for several important reasons. Children's skin is thinner than 
adults, and their surface area to body mass is much higher. ${ }^{4}$ During heating, children also have elevated skin temperatures when compared to adults, indicating higher levels of peripheral vasodilatation. ${ }^{4}$ This allows faster heat transport (but also faster heat return as in this case.) Children also have a lower total blood volume per body mass than adults, presenting decreased cooling opportunity and also a potential for decreased central and brain blood flow when blood is diverted from central circulation to the periphery. ${ }^{4}$ The combination of these two vulnerabilities means that children raise their core temperatures much faster than adults and thus face a faster and higher risk of hyperthermia, especially when the peripheral circulatory increase only serves to return heated blood into the circulation. ${ }^{5}$

\section{Cardiac Output}

Simple aquatic immersion produces a long-recognized increase in cardiac output. ${ }^{6-10}$ This has not been studied in children during immersion. In land-based exercise in warm environments children do show increase in cardiac output but to a lesser degree than in adults. ${ }^{4}$ In a warm or hot environment, the first response of the body is to increase peripheral circulation, especially to skin surfaces to facilitate sweating. ${ }^{3}$ The magnitude of this response is substantial, increasing peripheral circulation $15 \mathrm{~cm}^{3} / \mathrm{min}$ for each $0.01^{\circ} \mathrm{C}$ rise in body temperature, with potentially a 25 -fold increase in cutaneous blood flow. ${ }^{3,11}$ Children have higher peripheral blood flow than adults in comparable high temperatures. ${ }^{4}$ While core temperature rises far more slowly than skin temperature, it is highly likely that the initial neurologic signaling from the skin is what triggers this response because this happens far quicker to protect thermal homeostasis. Work done in our laboratory demonstrated nearly a $1200 \%$ increase in peripheral circulation within the first 4 minutes of warm water $\left(39^{\circ} \mathrm{C}\right)$ immersion in young subjects, nearly double that seen in an older cohort. ${ }^{12,13}$ This increase in peripheral blood flow is facilitated by the increase in cardiac output, but the redistribution of blood reduces the blood flow to central structures and the brain. ${ }^{3}$ The speed with which this occurred was dramatic, with immediate increase in blood flow within seconds. In a warm water environment, the heated blood returns uncooled and even heated to the brain, signaling a demand for yet more peripheral blood flow, creating a vicious cycle until maximal peripheral flow is achieved. ${ }^{3}$

\section{Brain Metabolism and Blood Flow}

Despite the brain occupying only $2-3 \%$ of total body mass, the brain consumes around $20 \%$ of total body oxygen consumption. ${ }^{11}$ The brain has a very high overall metabolic rate, a single neuron consuming many hundred-fold the power consumption of an average body cell. ${ }^{14}$ This high level of metabolism causes the brain to normally operate at temperatures $0.3-0.8^{\circ} \mathrm{C}$ above core temperature, and this figure can rise substantially during increased demand periods, and particularly during hyperthermia. ${ }^{14}$ This temperature increase is normally managed by cerebral blood flow ( $\mathrm{CBF}$ ) bringing in cooler blood, so that there is a differential between arterial inflow and warmed venous outflow. In addition to providing oxygen and other needs to the brain, it also transports heat away from it. ${ }^{15}$ Recent publications on young adults have documented an increase in the cerebral metabolic rate of oxygen consumption $\left(\mathrm{CMRO}_{2)}\right.$ of $10-20 \%$ during hyperthermia. ${ }^{15,} 16$

Simple immersion and immersed exercise increases brain blood flow by significant amounts, although human studies to date have not yet included children. ${ }^{17-19}$ The studies demonstrating this used thermoneutral water temperatures rather than warm water. The normal increase in CBF from thermoneutral immersion is overwhelmed in the face of hyperthermia. The normal physiologic response to hyperthermia uses two mechanisms of cooling: hyperventilation and increasing cerebral blood flow. Hyperventilation typically produces a reduction in arterial $\mathrm{CO}_{2}$ pressure $\left(\mathrm{PaCO}_{2}\right)$, which causes cerebral vasoconstriction. ${ }^{11}$ This is one factor in reducing CBF. A 2020 study of passive thyperthermia corrected for this respiratory alkalosis by using an end-tidal forcing apparatus to correct $\mathrm{PaCO} 2$ to normothermic levels and found essential the same effects on cerebral metabolism elevation and cerebral blood flow reduction. ${ }^{16}$ As a consequence of a reduction in cerebral blood flow with a simultaneous increase in cerebral metabolism there is very real potential for cellular injury to brain cells. When brain temperatures reach $40^{\circ}$ to $41^{\circ} \mathrm{C}$, particular cell lines are damaged and when reaching $42^{\circ} \mathrm{C}$, irreversible damage occurs. ${ }^{3,} 20$ The duration of hyperthermia is particularly relevant in promoting cellular survival, so aggressive rapid cooling measures are essential. ${ }^{21}$ 


\section{Syncope}

Disorders of cerebral function and syncope can occur with decreases of CBF below $60 \%$ of normal. When CBF drops to only $40 \%$ of normal unconsciousness occurs in seconds. ${ }^{3}$ Syncope results during such a loss of $\mathrm{CBF}$, and is exacerbated by the increased $\mathrm{O}_{2}$ demands of a hypermetabolic brain. ${ }^{11}$

\section{Drowning}

Normally respiration does not cease with syncope, and on land when the person collapses, cerebral blood flow is increased, resulting in return to consciousness. When syncope occurs in an aquatic environment, the body attempts to breathe, but instead of taking in air, water enters the airway, triggering laryngospasm and consequent inability to breathe. This initiates the drowning process. ${ }^{22}$ With increasing hypoxia, the laryngospasm abates and further aspiration of water may occur. This often (30-50\%) results in post-drowning pneumonia in survivors. ${ }^{22}$ Such was the case in the case report above. When drowning occurs in cold water environments, the body and brain may cool sufficiently to prevent massive cerebral damage, but in heated water, the increase in brain metabolism combined with hypoxia may be catastrophic. ${ }^{22}$

\section{Hyperthermia following Cerebral Injury}

In the case report following immersion in an excessively heated body of water, the initial

hyperthermia was a passive consequence of that environment. It was followed by a prolonged period of resuscitation while laying on $139^{\circ} \mathrm{C}$ concrete for at least 20 minutes, resulting in burns to her back and extremities. As soon as her heart resumed function following CPR, the superheated blood in her trunk and extremities was returned to her central circulation and brain. Once she was hospitalized, aggressive attempts to cool were made. Over the following week or more, her temperature fluctuated dramatically. Traumatic brain injury is associated with aseptic hyperthermia in 30-70\% of pediatric cases, and is closely associated with the magnitude of brain injury and subsequent recovery. ${ }^{20,} 23$ As a result, current best practice is to provide cooling to normothermic or lower levels during the period following resuscitation of cardiac arrest or hospital care following TBI. ${ }^{23}$ The longer the brain is allowed to remain in a hypermetabolic state, the poorer the ultimate recovery. ${ }^{23}$

\section{Brain Injury}

The primary temperature sensitive elements of neural cells are mitochondrial and plasma membranes. ${ }^{20}$ The protein structures within these structures become disrupted and may undergo irreversible abnormalities at temperatures even above $40^{\circ} \mathrm{C} .{ }^{20}$ This is potentiated by hypoxia. ${ }^{20}$ Children with their rapidly developing brain cells may be at greater risk than adults, and while some cell death occurs quickly, other cells may undergo a prolonged period of apoptosis. ${ }^{20}$ Purkinje cells seem to be the most at risk, showing cellular changes to the greatest extent. ${ }^{20}$ As a consequence, the cerebellum may undergo the greatest damage with loss of motor control. ${ }^{20}$ This has been the case in the subject described above, with on-going deficits in gait function, bimanual motor control, and coordination.

\section{Discussion}

The frequency of the events described above is unknown; there is no national registry of pediatric drownings which includes causation. ${ }^{24}$ Drowning is the leading cause of injury and death in the USA between the ages of 1-4 and the $3^{\text {rd }}$ leading cause in the ages from 5-19 years of age. ${ }^{24}$ Supervision remains the most essential means of protection, but the Model Aquatic Health Code developed by the CDC is both based on science and standards for safety of operation. The code states maximum temperature "shall not exceed $104^{\circ} \mathrm{F} . "{ }^{25}$ The policy statement from the American Academy of Pediatrics referenced fails to mention hyperthermia risk from hot tub use. ${ }^{24}$ In the case scenario, these standards were not met: the hot tub temperature was substantially in excess of this code, and in actuality signage within the pool area failed to describe risks of overheating. There were no depth markers thus leaving visitors little forewarning of such risk. While the age of the case described was over the age of 5 , below which hot tub use is warned against by the CDC, she was close enough to have raised concerns. The presence of a hot tub with heater set to $104^{\circ} \mathrm{F}$ did not include any 
means of cooling should that temperature be exceeded, and it is unclear as to whether there was any means of alerting operators if this temperature was exceeded. There were no thermometers in the hot tub. While the mother did not accompany the child into the tub, she had believed that the tub was off, as the jets were not working, and her child was a skilled swimmer.

Hyperthermic syncope can occur suddenly in both children and adults, with potentially catastrophic results. It is poorly recognized as a risk by medical professionals, aquatic facility supervisors, lifeguards, and the general public. This case demonstrated the risks, the unfortunate outcome and the underlying physiology behind those risks.

\section{Prevention}

Far broader awareness of the risks of hyperthermia is needed by medical professionals, the lay public and aquatic facility owners. This event could have been prevented by a mother alerted to the risks presented by an overheated hot tub, made aware by signage and by available thermometers showing actual tub temperature. The aquatic attendant should have been aware of both the tub temperature and the risks thus presented, and equipped to manage adverse events. Facility management should have made adaptations to the hot tub to avoid such risks through appropriately covering the area to reduce solar gain, and setting the temperature no higher than $100^{\circ} \mathrm{F}$, as described in the Model Aquatic Health Code. Facility management should also have had better oversight of the tub vicinity than a single attendant over the entire large area.

\section{Funding Credits and Disclosure of Potential and Real Conflicts of Interest}

No external funding was used in preparation of this manuscript. I have no real or potential conflicts of interest.

\section{References:}

1. Duzinski SV, Barczyk AN, Wheeler TC, Iyer SS, Lawson KA. Threat of paediatric hyperthermia in an enclosed vehicle: a year-round study. Inj Prev. Aug 2014;20(4):220-225.

2. Hart LE, Egier BP, Shimizu AG, Tandan PJ, Sutton JR. Exertional heat stroke: the runner's nemesis. Can Med Assoc J.May 24 1980;122(10):1144-1150.

3. Bartlett A, Braun T. Death in a Hot Tub: The Physics of Heat Stroke. American Jl of Physics. 1983;51(127).

4. Falk B. Effects of thermal stress during rest and exercise in the paediatric population. Sports Med. Apr 1998;25(4):221-240.

5. Tsuzuki-Hayakawa K, Tochihara Y, Ohnaka T. Thermoregulation during heat exposure of young children compared to their mothers.Eur J Appl Physiol Occup Physiol. 1995;72(1-2):12-17.

6. Arborelius M, Jr., Balldin UI, Lilja B, Lundgren CE. Hemodynamic changes in man during immersion with the head above water.Aerosp Med. 1972;43(6):592-598.

7. Kinney EL, Cortada X, Ventura R. Cardiac size and motion during water immersion: implications for volume homeostasis. Am Heart J. 1987;113(2 Pt 1):345-349.

8. Lollgen H, von Nieding G, Koppenhagen K, Kersting F, Just H. Hemodynamic response to graded water immersion. Klin Wochenschr.1981;59(12):623-628.

9. Epstein M, Levinson R, Loutzenhiser R. Effects of water immersion on renal hemodynamics in normal man. J Appl Physiol.1976;41(2):230-233.

10. Becker BE. Aquatic Therapy: Scientific Foundations and Clinical Rehabilitation Applications. PMER. 2009;1(9):859-872.

11. Bain AR, Morrison SA, Ainslie PN. Cerebral oxygenation and hyperthermia. Front Physiol. 2014;5:92. 
12. Hildenbrand K, Becker B, Whitcomb R, Sanders J. Age-Dependent Autonomic Changes

Following Immersion in Cool, Neutral,and Warm Water Temperatures.International Journal of Aquatic Research and Education.2010;4(2):127-146.

13. Becker BE, Hildenbrand K, Whitcomb RK, Sanders JP. Biophysiologic Effects of Warm Water Immersion. International Journal of Aquatic Research \& Education. 2009;3(1):24-37.

14. Kiyatkin EA. Physiological and pathological brain hyperthermia. Prog Brain Res. 2007;162:219-243.

15. Fischer M, Tamariz-Ellemann A, Gliemann L. Hyperthermia: The hotter the body, the hungrier the brain? J Physiol. Jun 2020;598(11):2053-2054.

16. Bain AR, Hoiland RL, Donnelly J, et al. Cerebral metabolism, oxidation and inflammation in severe passive hyperthermia with and without respiratory alkalosis. $J$ Physiol. Mar 2020;598(5):943-954.

17. Pugh CJ, Sprung VS, Ono K, et al. The Effect of Water Immersion during Exercise on Cerebral Blood Flow. Med Sci Sports Exerc. Feb 2015;47(2):299-306.

18. Bonde-Petersen F, Schultz-Pedersen L, Dragsted N. Peripheral and central blood flow in man during cold, thermoneutral, and hot water immersion. Aviat Space Environ Med. 1992;63(5):346-350.

19. Carter HH, Spence AL, Pugh CJ, Ainslie P, Naylor LH, Green DJ. Cardiovascular responses to water immersion in humans: impact on cerebral perfusion. Am J Physiol Regul Integr Comp Physiol. May 2014;306(9):R636-640.

20. Walter EJ, Carraretto M. The neurological and cognitive consequences of hyperthermia. Critical care. Jul 14 2016;20(1):199.

21. Hickey RW, Kochanek PM, Ferimer H, Graham SH, Safar P. Hypothermia and hyperthermia in children after resuscitation from cardiac arrest. Pediatrics. Jul 2000;106(1 Pt 1):118-122.

22. Topjian AA, Berg RA, Bierens JJ, et al. Brain resuscitation in the drowning victim. Neurocrit Care. Dec 2012;17(3):441-467.

23. Natale JE, Joseph JG, Helfaer MA, Shaffner DH. Early hyperthermia after traumatic brain injury in children: risk factors, influence on length of stay, and effect on short-term neurologic status. Crit Care Med. Jul 2000;28(7):2608-2615.

24. Denny S, Quan L, Gilchrist J, et al. Prevention of Drowning. Pediatrics. 2019;143(5).

25. CDC. Model Aquatic Health Code. 2018; https://www.cdc.gov/mahc/pdf/2018-MAHC-Code-Clean508.pdf.

\section{Data Availability:}

Data sharing not applicable-no new data generated 